\title{
Are nasal steroids effective in children with adenoid hypertrophy?
}

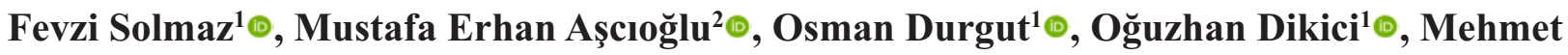 \\ Haksever $^{1} \odot$, Davut Akduman ${ }^{3} \odot$
}

\begin{abstract}
${ }^{1}$ Department of Otorhinolaryngology, University of Health Sciences, Bursa Yüksek İhtisas Training and Research Hospital, Bursa, Turkey

${ }^{2}$ Department of Pediatry, University of Health Sciences, Bursa Yüksek İhtisas Training and Research Hospital, Bursa, Turkey

${ }^{3}$ Department of Otorhinolaryngology, Düzce University School of Medicine, Düzce, Turkey
\end{abstract}

DOI: $10.18621 /$ eurj.405439

\begin{abstract}
Objectives: Chronic nasal obstruction is a common disease of childhood. Adenotonsillar hypertrophy plays an important role in obstructive sleep apnea. The topical use of the aerosolized forms of corticosteroids therefore seems the most appropriate route to decrease systemic side effects. The aim of our study is to demonstrate the effect of topical mometasone furoate especially on the adenoid volume in patients without any allergic story. Methods: The study group consisting of 30 males and 25 females was administered topical nasal mometasone furoate steroid treatment. The 20 patients were in the control group where saline solution $(0.9 \% \mathrm{NaCl})$ treatment was administered consisted of 12 males and 8 females. Nasopharyngeal X-rays before treatment revealed that 25 patients were Grade 2 and 30 patients were Grade 3 according to the Fujioka method.

Results: Flexible endoscopy performed before the treatment revealed that 20 patients were Grade 2, 11 patients were Grade 3 and 24 patients were Grade 4. Nasal endoscopies performed after 6 weeks of intranasal topical steroid therapy revealed that 45 patients were Grade 1 and 10 patients were Grade 2. A statistically significant difference was present between endoscopic grades before and after treatment $(p<0.0001)$. Nasal endoscopies performed after 6 weeks in control group receiving saline solution treatment revealed Grade 2 in 7 patients, Grade 3 in 10 patients and Grade 4 in 3 patients. There was no statistically significant difference between in the prior and later grades of the control group $(p=0.3125)$.

Conclusions: We believe that the use of intranasal steroids (mometasone furoate) for 6 weeks in patients with pediatric chronic nasal obstruction due to adenoid hypertrophy may be an effective treatment modality in alleviating symptoms and decreasing adenoid volume without causing systemic side effects.
\end{abstract}

Keywords: Nasal steroids, adenoid hypertrophy, flexible endoscopy, nasopharyngeal X-rays, Fujioka method

Received: March 13, 2018; Accepted: October 13, 2018; Published Online: November 8, 2018

O hronic nasal obstruction (CNO) is a common disease of childhood with an estimated prevalence of $2-3 \%$ in the healthy pediatric population [1]. Adenotonsillar hypertrophy plays an important role in obstructive sleep apnea (OSA) pathophysiology and reaches its peak incidence between the ages of 2 and 8 years $[2,3]$. OSA is the result of increased airway resistance during sleep and characteristically manifests as repeated arousals, hypercapnia, episodic snoring, and periods of oxyhemoglobin desaturation [4]. Ade-

Address for correspondence: Fevzi Solmaz, MD., University of Health Sciences, Bursa Yüksek Ihtisas Training and Research Hospital, Department of Otorhinolaryngology, Bursa,Turkey

E-mail:drfsolmaz@yahoo.com,Tel:+902242955000,Fax:+902243660416 
notonsillar hypertrophy is the most common cause of OSA in preschool children [5]. Allergic exacerbations give rise to the hypertrophy of adenoid tissue but repeated upper respiratory tract infections(URTIs) may also be the cause.

The hypertrophied lymphoid tissue may cause many pathological conditions including snoring, sleep apnea, sinusitis otitis media with effusion and adenoid face [6]. If left untreated, OSA may cause many serious problems such as cognitive and behavioral disorders, systemic and pulmonary hypertension, enuresis, and developmental delay [7]. Adenoidectomy is the definitive treatment modality for upper airway obstruction caused by adenoid hypertrophy but decongestant nasal drops have also been used for its symptomatic management [8].

Structural and neuromuscular pathologies may also cause $\mathrm{CNO}$ but the main factor in the pathogenesis of pediatric CNO is the size of the tonsils and adenoid tissue making their surgical excision the primary choice of treatment $[9,10]$. Postoperative residual OSAS is found in $20 \%$ of the children who have undergone adenotonsillectomy [11].

The nonsurgical treatment options for pediatric $\mathrm{CNO}$ are attracting increasing attention due to the potential complications of adenotonsillectomy. Anti-allergic drugs have been used from time to time despite the lack of adequate evidence to support their usage, as allergy is just one of the reasons for obstruction [12]. The efficacy of oral steroids in relieving the obstructive symptoms of adenoid hypertrophy is reported in the literature. They also reduce the size of the adenoid tissue significantly. However, their long-term use is limited due to the significant side effects [12]. The topical use of the aerosolized forms of corticosteroids therefore seems the most appropriate route to decrease systemic side effects, since there will be a minimal amount of systemic absorption from the upper airway [13]. The 6-week administration of triamcinolone acetonide aqueous nasal spray to children with allergic rhinitis aged 6 to 12 years has been reported to have no significant impact on adrenocortical function. Treatment with mometasone furoate aqueous nasal spray (200 micrograms once a day) for 14 days was shown to be safe and well-tolerated in children [14].

Local and systemic inflammatory markers and proinflammatory cytokines, which trigger lymphoid tissue proliferation, are increased in children with ade- notonsillar hypertrophy. Systemic or topical anti-inflammatory agents have therefore been recommended to prevent the potential tonsillar hypertrophy in these patients $[15,16]$. Topical nasal corticosteroids can alleviate $\mathrm{CNO}$ symptoms and nasal obstruction as well as reduce the size of the adenoid tissue $[17,18]$. However, the optimal dose and duration of treatment with nasal steroid agents is not clearly defined yet.

The current inadequate evidence on the efficacy of intranasal steroids in children with adenoid hypertrophy and nasal obstruction led us to conduct this study. With this study we evaluated the efficacy of Mometazon furoat (topical nasal steroid) on adenoid hypertrophy in children.

\section{METHODS}

\section{Patients}

The study was conducted a randomized placebocontrolled children with adenoid hypertrophy who presented to Otolaryngology and Pediatrics outpatient clinics of our hospital. All procedures performed in studies involving human participants were in accordance with the ethical standards of the institutional and/or national research committee and with the 1964 Helsinki declaration and its later amendments or comparable ethical standards. The Institutional review board (IRB) was taken for the patients (Number: 66519339-900-01/1304). Informed consent was obtained from all individual participants included in the study. Adenoidectomy operation under general anesthesia was suggested as the main treatment of adenoid hypertrophy to all parents or patients and they were informed about the possible complications of the operation. Mometazon furoat as topical nasal steroid was prescribed for the patients who rejected the surgery and for the relief of symptoms in case of preoperative severe symptoms. All the patients included in the study had a complaint of snoring, cessation of breathing and frequent arousals during sleep. They were aged between 6 to 12 years old.

The diagnosis of adenoid hypertrophy was based on endoscopic nasopharyngeal findings (the occlusion degree of the choana with adenoid tissue) and lateral cephalometric X-ray findings (the thickness of soft tissue density in nasopharyngeal airway) in patients 
suspected of having adenoid hypertrophy (i.e., having nasal obstruction without septoconchal pathology, snoring, and/or nasal discharge).

\section{The inclusion criteria were as follows:}

1. Patients aged between 6 to 12 years old,

2. With a diagnosis of adenoid hypertrophy without tonsillar hypertrophy for a minimum of 12 months,

3 . With a follow-up period of 2 months and per 2week intervals,

4. No sign of improvement despite medical treatment with antibiotics under parental control.

\section{The exclusion criteria were as follows:}

1. Use of any nasal or systemic steroid within the past 1 year.

2. Use of any nasal decongestant or anti-allergic medication within the past 2 weeks.

3. History of upper respiratory tract infection within the past 2 weeks.

4. History of one or more of the following conditions: genetic craniofacial, or neuromuscular syndromes, chronic epistaxis, immune disease, asthma, nasal surgery, septal perforation, nasal trauma within the last 3 months and hypersensitivity to mometazon furoat.

The patients with a diagnosis of adenoid hypertrophy who were candidates for surgery with a 6-weeks follow-up saline solution (3-5 drops, three times/day) treatment were included in the study as control group.

After taking a detailed medical history, the symptoms were graded according to the severity of patient's clinic. Pre-treatment a lateral cephalometric $\mathrm{X}$-ray graph and a nasopharyngoscopic image ("MSI Flexible Nasopharyngoscope, Germany" attached to "Karl-Storz Telecam SL II, Tuttlingen, Germany" camera) were obtained from every patient. The hypertrophy of adenoid tissue was graded. Follow up examinations were based on nasopharyngoscopic records. Nasopharyngoscopic examination records were repeated after medical treatment. The difference between pretreatment and post treatment adenoid tissue enlargement were compared.

\section{Diagnostic Criteria}

\section{Symptoms}

Nasal obstruction, snoring, and nasal discharge

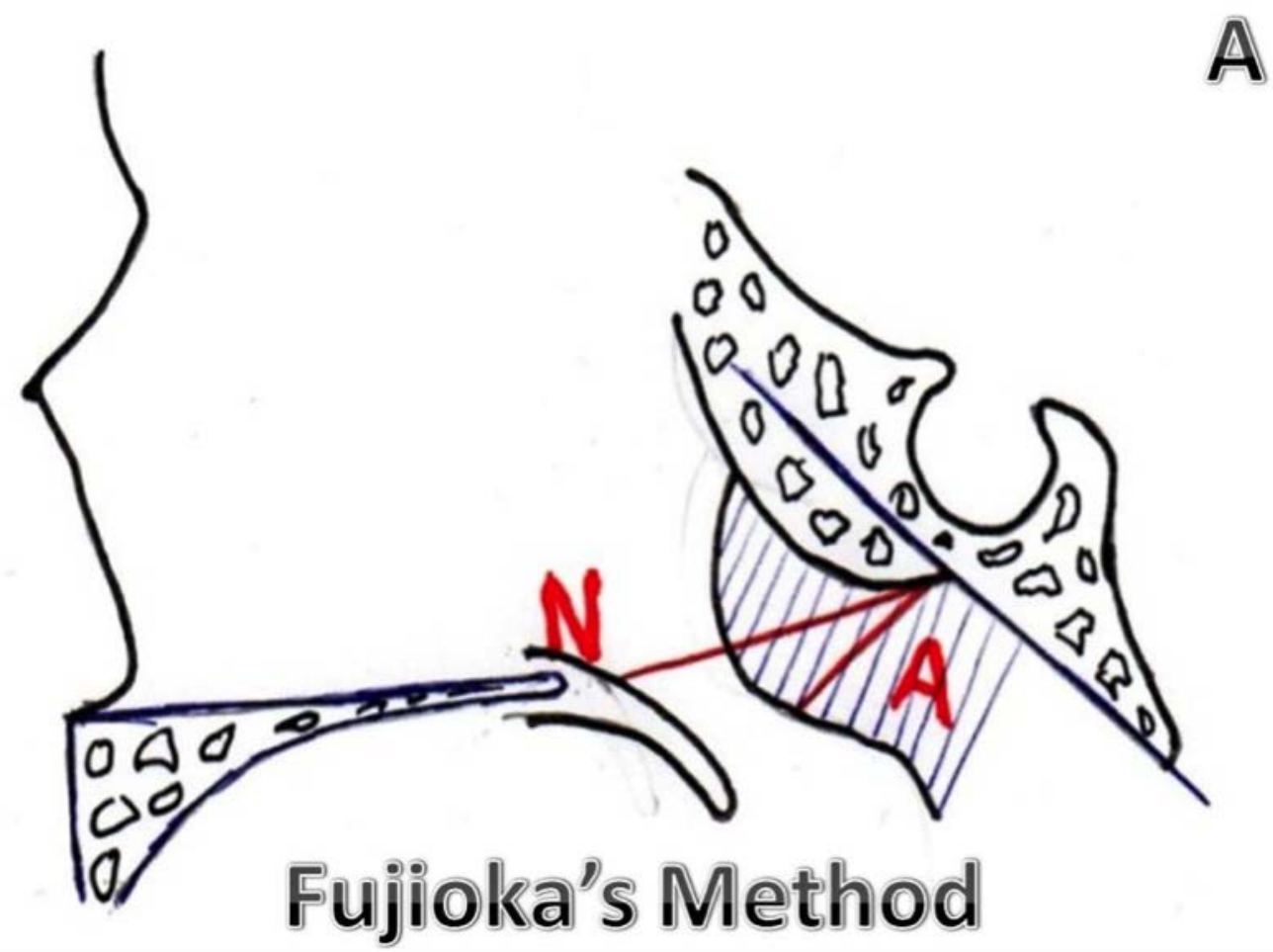

Figure A. Adeno/nasopharyngeal ratio according to the Fujioka method. 
were graded according to the frequency reported by the parents (Grade 0: never seen, Grade 1: seen during URTI, Grade 2: frequently seen, Grade 3: always occurs).

\section{Nasopharyngeal X-ray}

Adenoid tissue enlargement was graded according to the Adenoidal-nasopharyngeal ratios (ANR). The distance of adenoid tissue density was measured along a line dropped perpendicularly from point of maximal convexity of adenoid tissue to its point of intersection with line drawn along the straight part of the anterior margin of the basiocciput. Then the nasopharyngeal space was measured as the distance between posterior superior edge of hard palate and the anterior inferior edge of the spheno basioccipital synchondrosis. The ANR was obtained by dividing the measurement for adenoid tissue density by the value for nasopharyngeal space in millimeters as described by Fujioka et al. [19]. It was rated as: Grade 1: $>6 \mathrm{~mm}$, Grade 2: 4-6 $\mathrm{mm}$, and Grade 3: < $3 \mathrm{~mm}$. Nasal endoscopy: Performed with a Flexible Nasopharyngoscope following topical anesthesia with 4\% lidocaine without any decongestant. Graded according to the rate of obstruction of the choanal aperture by the adenoid tissue as Grade 1: 25\%, Grade 2: 50\%, Grade 3: $75 \%$, and Grade 4: $100 \%$ occlusion. Adeno/nasopharyngeal ratio according to the Fujioka method has been indicated in Figure A.

The children with a diagnosis of adenoidal hypertrophy were then prescribed topical mometasone furoate for 6 weeks, once a day, two puff to each nostril (50 mcg/puff), comprising a daily total dose of $200 \mathrm{mcg}$. The nasal endoscopic evaluations were repeated 6 weeks after the initial diagnostic workup.
Operation were not recommended to the control and study groups with grade 2 adenoid hypertrophy, however medical treatment was given.

\section{Statistical Analysis}

The data were analyzed with the SPSS for Windows v.16.0 software by IBM, USA.using the appropriate nonparametric tests for nominal and ordinal data. In all analytical evaluations, $p<0.05$ was the significance limit value.

\section{RESULTS}

The study consisted of 75 patients (42 male, 33 female) with adenoid hypertrophy aged between 6 to 12 years old. Demographic characteristics and Body Mass Index (BMI) and Percentiles of the study group and the control group have been indicated in Table 1 . Fifty-five patients (30 male, 25 female) who had topical nasal steroid accepted as study group and 20 patients (12 male, 8 female) who had preoperative follow up record for 6-weeks were accepted as control group. Endoscopic appearances before and after topical steroid treatment were indicated in Figures B, C and D.

The study group consisting of 30 males and 25 females was administered topical nasal Mometasone Furoate steroid treatment. Nasopharyngeal X-rays before treatment revealed that 25 patients were Grade 2 and 30 patients were Grade 3 grade according to the Fujioka method. Flexible endoscopy performed before the treatment revealed that 20 patients were Grade 2 , 11 patients were Grade 3 and 24 patients were Grade 4. Nasal endoscopies performed after 6 weeks of

Table 1. Demographic characteristics and BMI and percentiles of the study group and the control group

\begin{tabular}{lcc}
\hline & $\begin{array}{c}\text { Study Group } \\
(\mathbf{n}=\mathbf{5 5})\end{array}$ & $\begin{array}{c}\text { Control Group } \\
(\mathbf{n}=\mathbf{2 0})\end{array}$ \\
\hline Age (year) & $7.92 \pm 1.81$ & $7.80 \pm 1.36$ \\
& $(6-12)$ & $(6-11)$ \\
Gender (M/F) & $30 / 25$ & $12 / 08$ \\
Height (cm) & $125.47 \pm 11.30$ & $123.15 \pm 6.89$ \\
Weight (kg) & $28.72 \pm 7.09$ & $27.55 \pm 5.88$ \\
BMI & $17.94 \pm 1.58$ & $17.95 \pm 1.94$ \\
Percentile & $77.89 \pm 16.88$ & $78.95 \pm 13.83$ \\
BMI as a multiple of the mean & $1.11 \pm 0.07$ & $1.10 \pm 0.08$ \\
BMI & & \\
\hline
\end{tabular}

$\mathrm{BMI}=$ Body Mass Index, $\mathrm{F}=$ Female, $\mathrm{M}=$ Male 


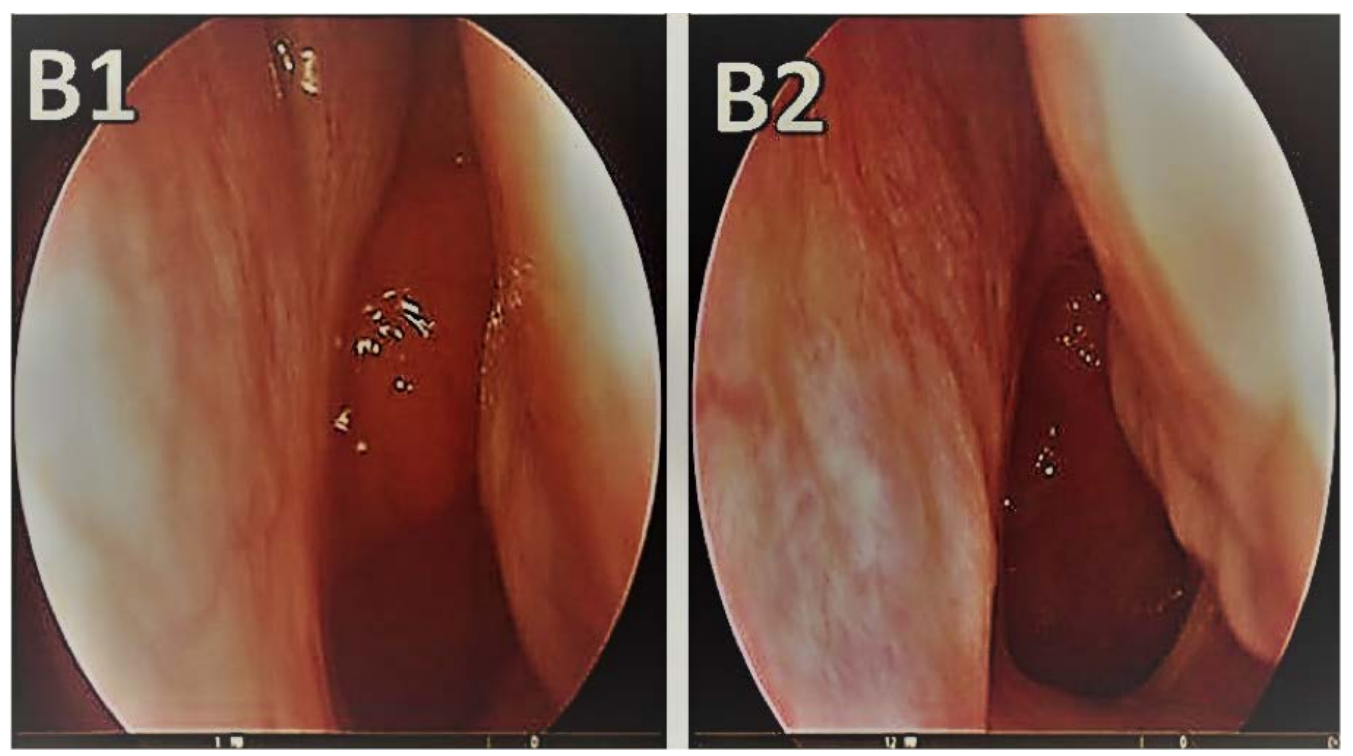

Figure B. Endoscopic appearance before (B1) and after (B2) topical steroid treatment.
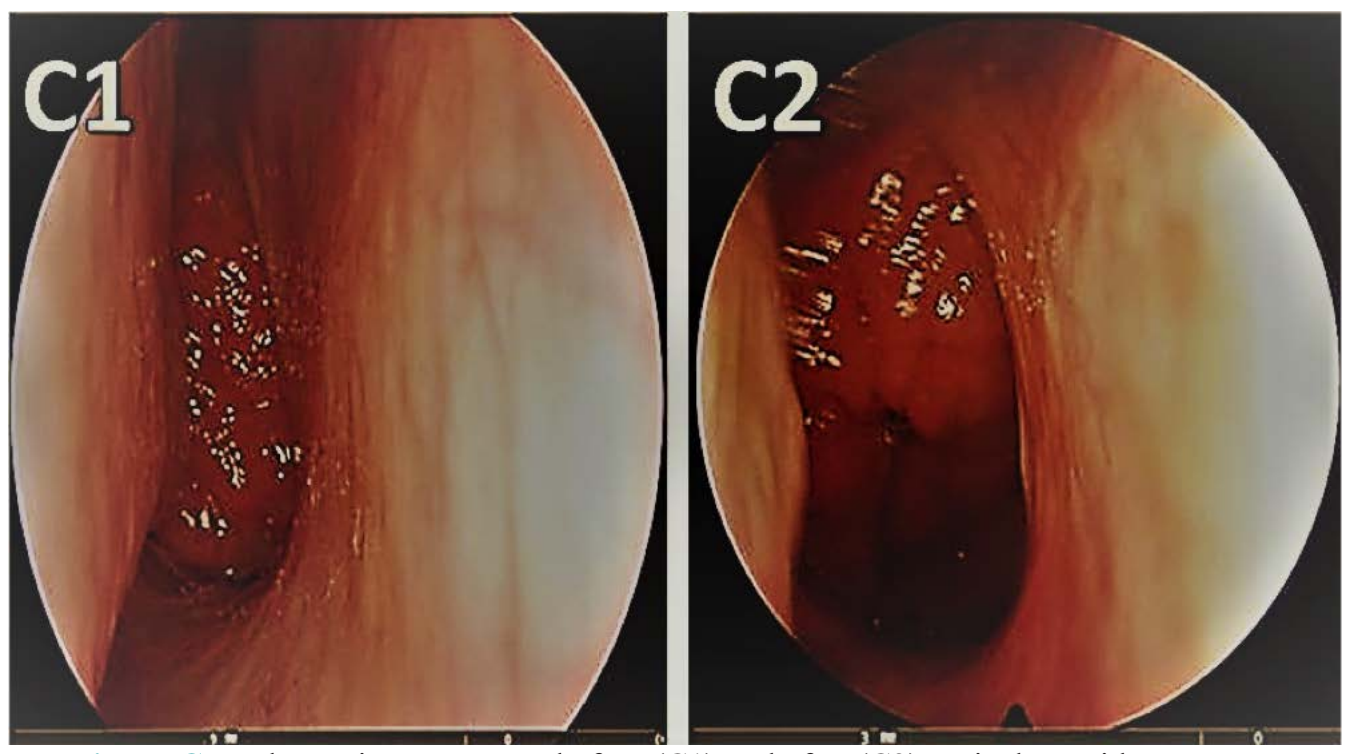

Figure C. Endoscopic appearance before (C1) and after (C2) topical steroid treatment.

intranasal topical steroid therapy revealed that 45 patients were Grade 1 and 10 patients were Grade 2. Nasopharyngeal X-rays were not requested for followup to avoid the additional harmful effects of X-rays. A statistically significant difference was present between endoscopic grades before and after treatment $(p<0.0001)$ (Table 2). Non-severe epistaxis was observed in three patients who administrated topical steroid therapy.

The 20 patients in the control group where saline solution $(0.9 \% \mathrm{NaCl})$ treatment was administered consisted of 12 males and 8 females. Nine patients was
Grade 2 and Grade 3 in 11 patients on nasopharyngeal $\mathrm{X}$-rays at first presentation according to the Fujioka method in this group. Flexible nasal endoscopy performed simultaneously revealed that there were Grade 2 in 6 patients, Grade 3 in 9 patients and Grade 4 in 5 patients. Nasal endoscopies performed after 6 weeks in control group receiving saline solution treatment revealed Grade 2 in 7 patients, Grade 3 in 10 patients and Grade 4 in 3 patients. There was no statistically significant difference between in the prior and later grades of the control group $(p=0.3125)$ (Table 2). 


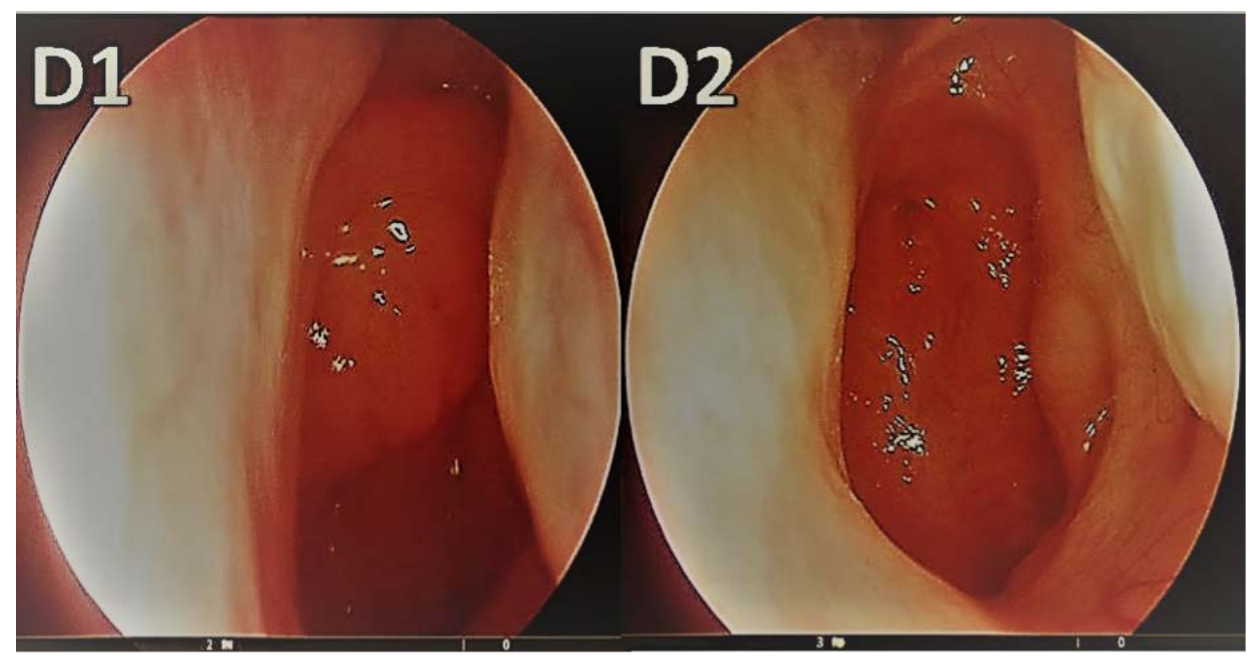

Figure D. Endoscopic appearance before (D1) and after (D2) topical steroid treatment.

Table 2. First and second endoscopic grades in the study group and in the control group

\begin{tabular}{lcccc}
\hline $\begin{array}{l}\text { Grade } \\
\text { n (\%) }\end{array}$ & $\begin{array}{c}\text { Study } \\
(\mathbf{n}=\mathbf{5 5})\end{array}$ & $\begin{array}{c}\text { Study } \\
(\mathbf{n}=\mathbf{5 5}) \\
\text { Second }\end{array}$ & $\begin{array}{c}\text { Control } \\
(\mathbf{n}=\mathbf{2 0}) \\
\text { First }\end{array}$ & $\begin{array}{c}\text { Control } \\
(\mathbf{n}=\mathbf{2 0}) \\
\text { Second }\end{array}$ \\
\hline Grade 1 & $0(0 \%)$ & $45(81 \%)$ & $0(0 \%)$ & $0(0 \%)$ \\
Grade 2 & $20(36 \%)$ & $10(18 \%)$ & $6(30 \%)$ & $7(35 \%)$ \\
Grade 3 & $11(20 \%)$ & $0(0 \%)$ & $9(45 \%)$ & $10(50 \%)$ \\
Grade 4 & $24(43 \%)$ & $0(0 \%)$ & $5(25 \%)$ & $3(15 \%)$ \\
Endoscopic grade (mean \pm SD) & $3.07 \pm 0.89$ & $1.18 \pm 0.38$ & $2.95 \pm 0.75$ & $2.80 \pm 0.69$ \\
\hline
\end{tabular}

*Wilcoxon test (paired samples).

\section{DISCUSSION}

Demain and Goetz [20] used beclomethasone nasal spray for 8 weeks ( $338 \mathrm{microgm} /$ day) followed by a lower daily dose (168 microgm/day) in the next 16 weeks for the treatment of adenoid hypertrophy and reported a decrease in adenoid size in all the study subjects. A history of atopy was reported in previous studies but they excluded those with such a history in this study [20]. We treated 55 children between the ages of 6 and 12 years with mometasone furoate nasal spray at a daily dose of $200 \mathrm{mcg}$ for 4 weeks [20]. Lepcha et al. [21] reported no significant improvement in X-ray and endoscopy findings of subjects administered intranasal topical beclomethasone for 8 weeks while there was a $6 \%$ improvement in nasal congestion. However, there was an improvement in adenoidal obstruction and clinical findings when compared with placebo after 24 weeks of treatment [21]. In our patients, we also observed a decrease in the endoscopic findings of adenoid tissues.
Kheirandish-Gozal and Gozal [4] showed intranasal budesonide to decrease the severity of respiratory distress and the size of the adenoids, although mildly, with 6 weeks of use in children with mild OSA. Brouillette et al. [17] observed an improvement in the respiration of patients despite no noticeable change in the adenoid tissue mass after 6 weeks of treatment with intranasal fluticasone before T\&A surgery in patients with moderate-to-heavy OSA. No significant change was found in the size of adenoids and tonsils and in the symptoms as reported by the parents but there was a significant reduction in apnea and hypopnea frequency among children treated with fluticasone.

Similar positive effects in OSA patients were reported in later studies. It is interesting that the effect on OSA symptoms continued even after the treatment was discontinued during 9 months of follow-up in the Alexopoulos et al. [18] study on 27 patients. The general results regarding OSA severity are strikingly similar despite differences in patient selection criteria 
and treatment methods, indicating that nasal corticosteroids can be used as the first treatment option in pediatric OSA. However, there is no clear consensus on the appropriate steroid dosage and treatment duration at present [16, 22]. Junk et al. [23] have reported a significant improvement in loud snoring, breath holding, frequent awakening from sleep, breathing from the mouth, URTI frequency and nasal discharge after 4 weeks of intranasal mometasone furoate treatment in children. We also chose mometasone furoate among the various steroid nasal sprays commercially available for this study. The reason was the absence of reports on any negative effect of this spray on the nasal mucosa or side effects related to the hypothalamus-pituitary-adrenal axis and growth with long-term use [24]. The systemic effect of the drug is lower than other steroids after topical administration [25]. Berlucchi et al. [26] recently evaluated the effectiveness of 40 days of mometasone furoate treatment in adenoid hypertrophy and found symptomatic improvement in $77.7 \%$ of the patients. Fujioka et al. [19] described the $\mathrm{A} / \mathrm{N}$ ratio as an indicator of adenoid hypertrophy in 1979 and the method has been used in many studies. Jung et al. [23] showed that the $\mathrm{A} / \mathrm{N}$ ratio on lateral neck graphs decreased in $22(71 \%)$ of 31 children after 4 weeks of treatment $(\mathrm{p}=0.006)$. Cengel and Akyol [27] reported shrinkage of adenoid tissue in $67.2 \%$ of the children after 6 weeks of treatment with intranasal mometasone furoate treatment in 2006. However, there is no proven mechanism explaining adenoid shrinkage. The presence of inflammation in the soft palate mucosal surface has been shown in OSA patients [28]. Jung et al. [23] thought that this type of upper respiratory tract inflammation could also involve the adenoid mucosa and that 4 weeks of local steroids could decrease this inflammation, causing the adenoids to shrink.

There are several methods to evaluate the size of the adenoids causing sleep-disordered breathing. The most commonly used techniques are lateral neck radiograph and direct videorhinoscopy. Mlynarek et al. [29] reported video rhinoscopy to be more useful for the evaluation of symptom severity in 2004. However, the nasopharyngeal examination of small children with fiberoptic devices can be difficult. The above results indicate that intranasal steroids can be used to reduce symptoms in children with sleepdisordered breathing, regardless of allergy or sinusitis.
The results of our study were also consistent with the literature. However, a limitation of our study is the lack nasal airway patency evaluation with objective methods such as acoustic rhinometry.

\section{CONCLUSION}

We believe that the use of intranasal steroids (mometasone furoate) for 6 weeks in patients with pediatric chronic nasal obstruction due to adenoid hypertrophy may be an effective treatment modality in alleviating symptoms and decreasing adenoid volume without causing systemic side effects. Placebo-controlled studies are required to investigate the long-term effect of short-term steroid use in the treatment of pediatric sleep disorders in the future.

\section{Conflict of interest}

The authors disclosed no conflict of interest during the preparation or publication of this manuscript.

\section{Financing}

The authors disclosed that they did not receive any grant during conduction or writing of this study.

\section{REFERENCES}

[1] Lumeng JC, Chervin RD. Epidemiology of pediatric obstructive sleep apnea. Proc Am Thorac Soc 2008;5:242-52.

[2] O'Brien LM, Holbrook CR, Mervis CB. Sleep and neurobehavioral characteristics of 5- to 7-year-old children with parentally reported symptoms of attention-deficit/hyperactivity disorder. Pediatrics 2003;111:554-63.

[3] Blunden S, Lushington K, Lorenzen B, Wong J, Balendran R, Kennedy D. Symptoms of sleep breathing disorders in children are underreported by parents at general practice visits. Sleep Breath 2003;7:167-76.

[4] Kheirandish-Gozal L, Gozal D. Intranasal budesonide treatment for children with mild obstructive sleep apnea syndrome. Pediatrics 2008;122;e149-55.

[5] Marcus CL. Sleep-disordered breathing in children. Am J Respir Crit Care Med 2001;164:16-30.

[6] Raphael G, Kaliner M. The tonsils and adenoids: Allergy and the pharyngeal lymphoid tissue. In Otolaryngologic Clinics of North America. Edited by Kornblut AD, Saunders WB: Philadelphia, 1987:pp. 295-303.

[7] Capdevila OS, Kheirandish-Gozal L, Dayyat E, Gozal D. Pediatric obstructive sleep apnea: complications, management, and long-term outcomes. Proc Am Thorac Soc 2008;5:274-82. 
[8] Cowan DL, Hibbert J. Tonsils and adenoids: In Scott Browns Pediatric Otolaryngology (Vol. 6) 6th edition. Edited by Kerr AG, Adams DA, Cinnamond MJ. Butterworth Heinemann, Oxford Chpt 1997;18, p.4-8.

[9] Li AM, Wong E, Kew J, Hui S, Fok TF. Use of tonsil size in the evaluation of obstructive sleep apnoea. Arch Dis Child 2002;87:156-9.

[10] Schechter MS. Technical report: diagnosis and management of childhood obstructive sleep apnea syndrome. Section on Pediatric Pulmonology, Subcommittee on Obstructive Sleep Apnea Syndrome. Pediatrics 2002;109: e69.

[11] American Academy of Pediatrics. Clinical practice guideline: diagnosis and management of childhood obstructive sleep apnea syndrome. Pediatrics 2002;109:704-12.

[12] Brodsky L. Modern assessment of tonsil and adenoids. Pediatr Clin North Am 1989;36:1551-69.

[13] Tracy JM, Demain JG, Hoffman KM, Goetz DW. Intranasal beclomethasone as an adjuvant to treatment of chronic middle ear effusion. Ann Allergy Asthma Immunol 1998;80:198-206.

[14] Brannan MD, Herron JM, Affrime MB. Safety and tolerability of once-daily mometasone furoate aqueous nasal spray in children. Clin Ther 1997;19:1330-9.

[15] Kheirandish-Gozal L, Serpero LD, Dayyat E, Kim J, Goldman JL, Snow A. Corticosteroids suppress in vitro tonsillar proliferation in children with obstructive sleep apnoea. Eur Respir J 2009;33:1077-84.

[16] Goldbart AD, Goldman JL, Veling MC, Gozal D. Leukotriene modifier therapy for mild sleep disordered breathing in children. Am J Respir Crit Care Med 2005;172:364-70.

[17] Brouillette RT, Manoukian JJ, Ducharme FM, Oudjhane K, Earle LG, Ladan S. Efficacy of fluticasone nasal spray for pediatric obstructive sleep apnea. J Pediatr 2001;138:838-44.

[18] Alexopoulos EI, Kaditis AG, Kalampouka E, Kostadima E, Angelopoulos NV, Mikraki V. Nasal corticosteroids for children with snoring. Pediatr Pulmonol 2004;38:161-7.

[19] Fujioka M, Young LW, Girdany BR. Radiographic evaluation of adenoidal size in children: adenoidalnasopharyngeal ratio. Am J Roentgenol 1979;133:401-4.

[20] Demain JG, Goetz DW. Pediatric adenoidal hypertrophy and nasal airway obstruction: reduction with aqueous nasal beclomethasone. Pediatrics 1995;95:355-64.

[21] Lepcha A, Kurien M, Job A, Jeyaseelan L, Kurien T. Chronic adenoid hypertrophy in children - is steroid nasal spray beneficial? Indian J Otolaryngol Head Neck Surg 2002;54:2804.

[22] Kheirandish L, Goldbart AD, Gozal D. Intranasal steroids and oral leukotriene modifier therapy in residual sleep-disordered breathing following tonsillectomy and adenoidectomy in children. Pediatrics 2006;117:e61-6.

[23] Jung YG, Kim HY, Min JY, Hun JD, Seung KC. Role of intranasal topical steroid in pediatric sleep disordered breathing and influence of allergy, sinusitis, and obesity on treatment outcome. Clin and Exp Otorhinolaryngol 2011;4:27-32.

[24] Minshall E, Ghaffar O, Cameron L, O’Brien F, Quinn H, Rowe-Jones J. Assessment by nasal biopsy of long-term use of mometasone furoate aqueous nasal spray (Nasonex) in the treatment of perennial rhinitis. Otolaryngol Head Neck Surg 1998;118:648-54.

[25] Boner AL. Effects of intranasal corticosteroids on the hypothalamic-pituitary-adrenal axis in children. J Allergy Clin Immunol 2001;108:32-9.

[26] Berlucchi M, Salsi D, Valetti L, Parrinello G, Nicolai P. The role of mometasone furoate aqueous nasal spray in the treatment of adenoidal hypertrophy in the pediatric age group: preliminary results of a prospective, randomized study. Pediatrics 2007;119:e1392-7.

[27] Cengel S, Akyol MU. The role of topical nasal steroids in the treament of children with otitis media with effusion and/or adenoid hypertrophy. Int $\mathrm{J}$ Pediatr Otorhinolaryngol 2006;70:639-45.

[28] Kimoff RJ, Hamid Q, Divangahi M, Hussain S, Bao W, Naor $\mathrm{N}$. Increased upper airway cytokines and oxidative stress in severe obstructive sleep apnoea. Eur Respir J 2011;38:89-97.

[29] Mlynarek A, Tewfik MA, Hagr A, Manoukian JJ, Schloss MD, Tewfik TL. Lateral neck radiography versus direct video rhinoscopy in assessing adenoid size. J Otolaryngol 2004;33:3605 . 